\title{
PRICE EFFECTS OF INDEPENDENT TRANSMISSION SYSTEM OPERATORS IN THE UNITED STATES ElECTRICITY MARKET
}

\author{
Theodore J. Kury ${ }^{1}$
}

\begin{abstract}
In 1996, the Federal Energy Regulatory Commission sought to "remove impediments to competition in the wholesale bulk power marketplace and to bring more efficient, lower cost power to the Nation's electricity consumers" through a series of market rules. A product of these rules was the establishment of regional transmission organizations (RTOs) and independent system operators (ISOs) charged with facilitating equal access to the transmission grid for electricity suppliers. Whether these changes in market structure have succeeded in achieving the FERC's goal to provide "lower cost power to the Nation's electricity consumers" remains an open question.

We utilize a panel data set of the 48 contiguous United States and a treatment effects model in first differences to determine whether there have been changes in delivered electric prices as a result of the establishment of ISOs and RTOs. To avoid the confounding effects of electric restructuring, we have initially estimated the model with the full panel data set, and then again without the states that have restructured their electric markets. By considering only the states that have not restructured their electric markets, we can see whether there have been price effects due to the establishment of RTOs, in the absence of restructuring agreements.

We estimate a model of annual changes in electricity prices using 2SLS and show that electricity prices fall approximately $4.9 \%$ in the first 2 years of an ISO's operation and that this result is statistically significant. However, we further show that this result is dependent on the presence of states that restructured their electricity markets and the accompanying rate agreements and temporal subsidies that may have forced prices below their market rates. When these restructured states are removed from the data set the price effects of RTOs become indistinguishable from zero. However, there may be some reductions in price for residential and industrial customers, when these classes are considered separately. We conclude that rate agreements are the principal source of the observed decrease in prices and that RTOs have not had the desired effect on electricity prices.
\end{abstract}

\footnotetext{
${ }^{1}$ Director of Energy Studies, Public Utility Research Center, University of Florida. I wish to thank Chunrong Ai, David Brown, Sarah Hamersma, Jon Hamilton, David Sappington, Sanem Sergici, and the participants at the $9^{\text {th }}$ International Industrial Organization Conference in Boston for their helpful comments. All remaining errors are my own.
} 


\section{$1 \quad$ Introduction}

Before the Federal Energy Regulatory Commission (FERC) issued its landmark Order 888 in April of 1996, the electricity generation, transmission, and distribution market in the United States had functioned largely within a vertically integrated monopoly structure for over 100 years. The opening paragraph in Order 888 reads:

"Today the Commission issues three final, interrelated rules designed to remove impediments to competition in the wholesale bulk power marketplace and to bring more efficient, lower cost power to the Nation's electricity consumers. The legal and policy cornerstone of these rules is to remedy undue discrimination in access to the monopoly owned transmission wires that control whether and to whom electricity can be transported in interstate commerce. A second critical aspect of the rules is to address recovery of the transition costs of moving from a monopoly-regulated regime to one in which all sellers can compete on a fair basis and in which electricity is more competitively priced."2

The FERC appears to believe that the vertically integrated structure in which the generator of electricity also controls the transmission of electricity is inefficient, and that this inefficiency leads to prices that are higher than they 'should' be. The issuance of this order paved the way for numerous states to introduce plans to restructure their electric markets, with varying degrees of success. This movement began most notably in California, Texas, and a number of states in the Northeast. This restructuring involved the separation of the utility's generation from the transmission and distribution functions. To facilitate non-discriminatory access for all generators

\footnotetext{
${ }^{2}$ FERC Order 888, issued April 24, 1996, Page 1 (75 FERC II 61,080)
} 
to the transmission grid, the FERC conditionally approved the formation of 5 independent system operators (ISO) in 1997 and 1998 to oversee the deregulated wholesale power markets. In December of 1999, FERC issued Order 2000, which stated: “The Federal Energy Regulatory Commission (Commission) is amending its regulations under the Federal Power Act (FPA) to advance the formation of Regional Transmission Organizations (RTOs). The regulations require that each public utility that owns, operates, or controls facilities for the transmission of electric energy in interstate commerce make certain filings with respect to forming and participating in an RTO. The Commission also codifies minimum characteristics and functions that a transmission entity must satisfy in order to be considered an RTO. The Commission's goal is to promote efficiency in wholesale electricity markets and to ensure that electricity consumers pay the lowest price possible for reliable service."3

This Order suggests that FERC believed that the establishment of independent entities to control access to the electric transmission system would result in costs that are no greater than the costs that exist at the time of the order. Further, it would preferable if the resulting costs were lower.

An RTO can impart many benefits to the market in both the short term and long term. First, through the optimization of the daily and hourly decisions of system dispatch, the RTO may lower the system costs required to serve electric load. By allowing non-discriminatory access to the transmission system, the RTO may also be able to incorporate lower priced resources that may not have enjoyed access to the market under a previous market regime, thus lowering system costs. Fabrizio, Rose, and Wolfram (2007) provide evidence that electric generators increase their operating efficiency in a market environment by reducing labor and

\footnotetext{
${ }^{3}$ FERC Order 2000, issued December 20, 1999, Page 1 (89 FERC II 61,285)
} 
nonfuel operating expenses, relative to operators in states that do not restructure their markets. An RTO may also be able to improve the reliability of the electric system by coordinating resource allocation and long term system planning. But all of these benefits must be measured against the costs of operating and maintaining the RTO, and the costs incurred by market participants for compliance and regulation. However, since all costs related to the RTO are recovered through volumetric charges passed through to consumers of electricity served by that RTO, it is possible to assess the RTO's effect on system costs net of the RTO's own costs by examining the rates charged to customers. Any change in prices, controlling for other factors, should signal either a net cost or net benefit associated with the RTO.

The FERC is presently attempting to assess the costs and benefits of RTOs. In February of 2010, the FERC issued a request for comments on a series of performance metrics for ISOs and RTOs. This request for comment was the result of a 2008 report from the Government Accounting Office that requested that the FERC work to develop metrics to track the performance of RTO operations and report this performance to the public. Once this data is collected, regulators will have better information with which to address the question, but the goal of this paper is to see if there is something that we can learn now, with the data we have available. Pricing metrics utilized by the FERC include indicators of wholesale market price performance, but do not reflect the costs paid by retail utility customers. Any burden to the retail customer will include not only the wholesale market prices, but the utility's costs of compliance. As a result, the FERC performance metrics account for some of the costs to retail customers, but do not address all of them. In an effort to assess the costs of maintaining a RTO, Greenfield and Kwoka (2010) have developed an econometric model of RTO costs dependent upon the geographic scale, scope of services provided, and age of the RTO. Such a model could be used to 
benchmark the relative cost effectiveness of these organizations. Kwoka, Pollitt, and Sergici (2010) have also presented evidence that forced divestiture as a result of electric restructuring has resulted in decreases in efficiency for electric distribution systems. Because these models do not address benefits, the question of whether RTOs have provided net benefits the consumers of electricity remains open.

This study employs a panel data set of the contiguous United States spanning the period 1990-2007 in an attempt to determine whether the establishment of RTOs has had an effect on the rates charged to consumers of electricity. We find that the price effects of RTOs, when disentangled from the effects of electric restructuring, are not statistically significant, and these results are robust to various specifications of the model. However, when the price effects for individual classes of customers are considered, there may be some slight reductions in price for residential and industrial customers.

The remainder of the paper consists of a discussion of the existing literature, the specification of the model of electricity costs, the results of the 2SLS estimation, and some concluding remarks.

\section{$2 \quad$ Existing Literature}

In 1937, Ronald Coase addressed the question of why individuals organize into firms, observing that the degree of vertical integration varied greatly among types of industries and types of firms. Since individuals were always free to interact with the market in the absence of firms, Coase concluded that firms arise when the costs of interacting with the market exceed the costs of interacting within an organization. So, if the regulators of a particular industry felt that the costs of interacting within an organization exceed those of the market, they might be compelled to restructure the firms in the industry in order to reduce transaction costs. 
Grossman and Hart (1986) have argued that the literature on transaction costs emphasized the conclusion that nonintegrated relationships can be inferior to relationships with complete contracts. However, this is not due to the nature of the nonintegrated relationship itself, but because of the presence of incomplete contracts. They pointed out that this argument assumes that integration leads to complete contracts, which may not be the case. They further argue that the proper comparison is that between contracts that allocate rights of ownership, residual rights, to one party and contracts that allocate them to another. They conclude that when it is too costly to specify a list of particular rights that one party desires over another party's assets, it may be optimal to purchase all rights.

Previous studies in this area have focused on the question of whether restructuring of the electricity market itself has led to changes in delivered electricity prices. Kwoka (2006) presents a review of a number of these studies. He finds that all are plagued by the confounding effects of settlement agreements between the states and the utilities in the state that were necessary to enable each state's restructuring plans. The particular terms of these settlement agreements varied considerably by state, but contained two common elements. The first element was some form of retail rate control, either a rate freeze that kept rates at current levels for a designated period of time, or a prescribed schedule of future rates based on current rates. Most often, the first year in the schedule mandated a rate decrease, and this decrease often persisted beyond the first year. The second element was a mechanism to recover the value of stranded assets, or to recover costs not recovered under the rate agreement. Restructuring in Pennsylvania, for example, was accompanied by the imposition of retail rate caps on the privately-owned utilities. The expiration of the rate caps for PPL Electric Utilities in January of 2010 was accompanied by rate increases of 30\%. Significant increases were also anticipated when the rate caps for Exelon 
Corporation and Allegheny Energy expire at the beginning of 2011. This dramatic increase in electric prices suggests that the realized prices in the years following the restructuring agreement did not reflect the market price for power in Pennsylvania. The states of Maryland and California experienced similar price increases upon the expiration of imposed price caps, so the experiences of the state of Pennsylvania are not unique. Clearly, some degree of 'cost savings' from electric restructuring was simply a temporal subsidy, though it is not yet clear how much, as cost recovery continues in many states, and the methods used to impose this subsidy were heterogeneous across states. Because temporal subsidies have been used to shift costs, the full effect of these subsidies is unknown and the effect of restructuring on costs is difficult to determine. Therefore, any analysis utilizing electricity prices in restructured states will be tainted by those confounding effects.

The present study frames the question differently to avoid those confounding effects. Rather than attempt to explain the changes in price wrought by electric restructuring, which is composed of two effects ${ }^{4}$, we have focused on whether there have been changes in price as a result of the formation of independent system operators (ISO) or regional transmission organizations (RTO). While there are structural differences ${ }^{5}$ between the two types of organizations, their basic function of ensuring equal access for electric generators to the transmission grid and optimal dispatch of the generating system remain. Since that is the function we are concerned with, the terms ISO or RTO in this paper can be read to refer to either type of organization. A map of the current footprint of these organizations is shown in Figure 1.

\footnotetext{
${ }^{4}$ The two effects are the effect of the change in market structure as well as the effect of the rate agreement used to facilitate electric restructuring.

${ }^{5}$ For example, RTOs have been tasked by the FERC to ensure the long term reliability of the system by managing transmission investment. ISOs are nominally regulated by the Federal government, while RTOs govern themselves.
} 


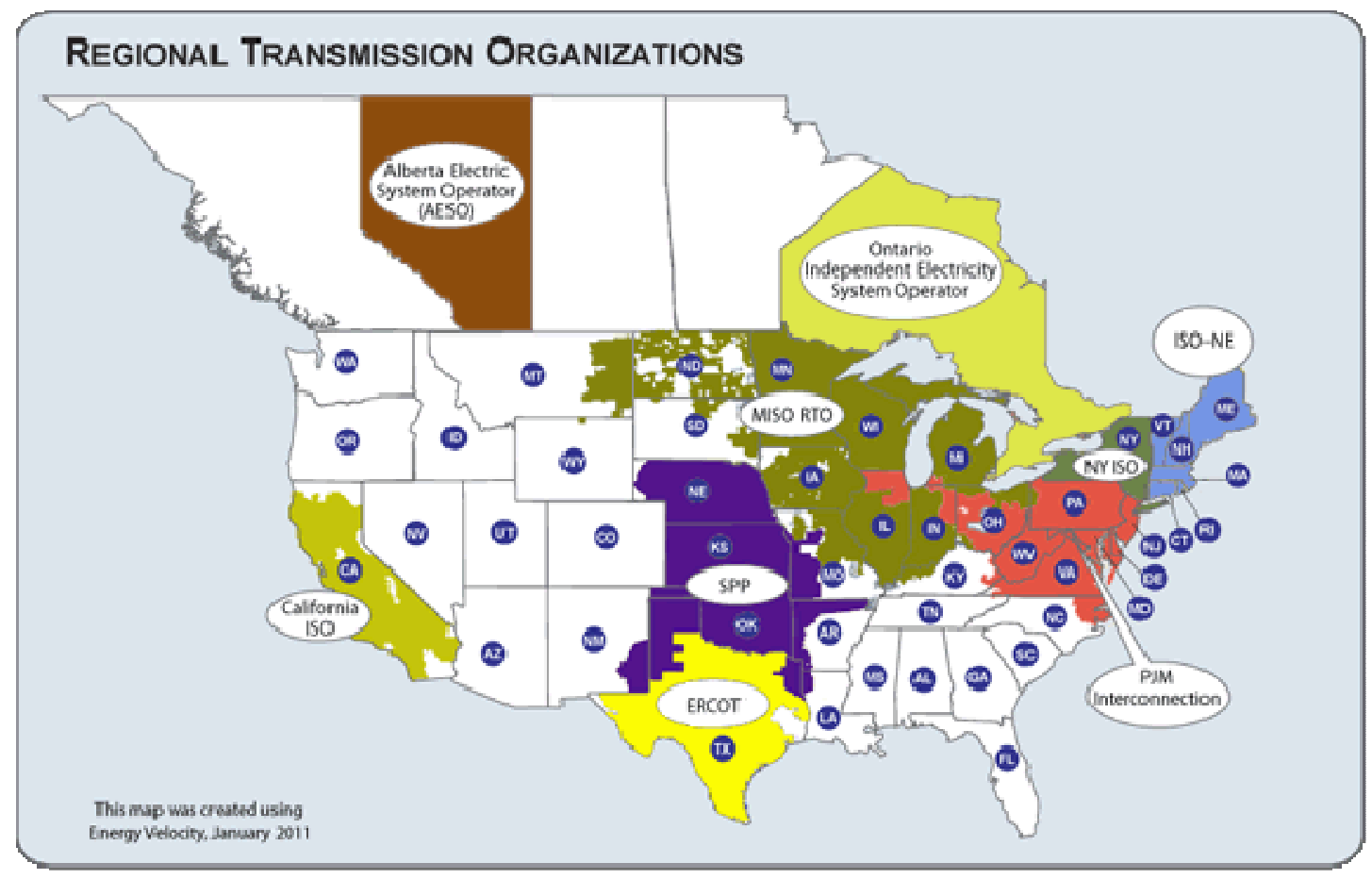

Figure 1. Regional Transmission Organizations in North America ${ }^{6}$

Using a panel data set of the 48 contiguous United States, we utilize a treatment effects model in first differences to determine whether there have been changes in delivered electric prices as a result of the establishment of RTOs. To avoid the confounding effects of electric restructuring, we have initially estimated the model with the full panel data set as a benchmark, and then again without the 16 states that have restructured their electric markets. Of the remaining 32 states, 12 are served by one or more RTOs. By considering only the states that have not restructured their electric markets, we can see whether there have been price effects due to the establishment of RTOs, in the absence of restructuring agreements.

\section{Data}

The data used in this paper are annual data for the 48 contiguous United States, spanning the period 1990 through 2008. The data for the study are primarily derived from reports and survey forms prepared by the United States Department of Energy's Energy Information

\footnotetext{
${ }^{6}$ From http://www.ferc.gov/industries/electric/indus-act/rto.asp
} 
Administration (EIA). The EIA is mandated by Congress to collect survey data from electric utilities in the United States. These data are collected on a variety of forms spanning electric utility operations. The EIA-860 report consists of generator-specific data such as generating capacity and energy sources. The EIA-861 and EIA-826 reports contain utility-specific data on sales and revenues by customer class. The EIA-923 report contains utility-specific data on electricity generation and fuel consumption. This utility- and generator-specific data is aggregated by state as a component of the EIA's State Energy Data System, the primary data source for statewide generation and prices in this study. Prices used in this study are average prices across customer classes, as well as for broad customer classes, calculated by dividing revenue by the sales volume. State-level data on annual heating and cooling degree days is available from the National Climatic Data Center, which population-weights the heating and cooling degree days collected from individual climate monitoring stations. Heating and cooling degree days are functions of average daily temperature often used to explain demand for electricity ${ }^{7}$. They are the aggregate of the average daily temperatures either above (cooling) or below (heating) 65 degrees Fahrenheit. For example, if the average daily temperature is 70 degrees, then that day is said to have 5 cooling degrees ${ }^{8}$. These degree days are then aggregated annually or monthly. Data on annual population by state is from the U.S. Census Bureau. Data regarding state participation in electric restructuring activities is available from EIA ${ }^{9}$, the FERC, and the individual state regulatory agencies. Finally, the membership of state utilities in RTOs is available from EIA, FERC (as seen in Figure 1), and the individual RTOs.

\section{The Model}

\footnotetext{
${ }^{7}$ See, for example, Papalexopoulos and Hesterberg (1990)

${ }^{8}$ If, for example, half of a state's population experiences 70 degree temperatures and half of the population experiences 74 degree temperatures, then the National Climatic Data Center will record 7 cooling degrees for that state, for that day.

${ }^{9}$ For example, http://www.eia.gov/cneaf/electricity/page/restructuring/restructure_elect.html
} 
We propose a model of the average electricity prices paid per kilowatthour $(\mathrm{kWh})$ of consumption by the customers in each state, and test the treatment effect of RTOs on that price. The effects of RTOs are not limited to prices, however. The centralization of dispatch and system planning decisions may have impacts beyond electricity revenues, such as on the overall system reliability. The effects of the RTOs on system reliability are much more difficult to assess, however, as most reliability data is proprietary. Further, the RTOs may be able to optimize the decisions regarding power plant investment within its region of responsibility, but this effect is an opportunity for further research, as its effects may not yet be seen. Thus, we have chosen to study the impact that RTOs have through the retail rates charged to customers. We feel that this is an important metric, as the portion of FERC Order 2000 cited above specifically states the Commission goal of lowest possible prices.

The average revenue per $\mathrm{kWh}$ of electricity for each state $i$, in a given year $t$ can be expressed by the following panel equation:

$$
\text { Price }_{i t}=\alpha_{i}+\beta_{0} \text { Sales }_{i t}+\beta_{1} \text { PCoal }_{i t}+\beta_{2} \text { PGas }_{i t}+\beta_{3} \% \text { Hydro }_{i t}+\beta_{4} \% N u c_{i t}+\beta_{5} R T O_{i t}+u_{i t}
$$

where:

Price Nominal state electricity revenues per $\mathrm{kWh}$ in cents $/ \mathrm{kWh}$

Sales Electricity sales in MWh

PCoal Nominal state price of coal in \$/MMBtu

PGas Nominal state price of natural gas in \$/MMBtu

\%Hydro Percent of electric generation from hydroelectric sources

$\%$ Nuc Percent of electric generation from nuclear sources

RTO Whether the majority of the electric customers in the state are served by a utility that belongs to an RTO 
The variable $\alpha$ represents the fixed effects of the model, or the heterogeneous characteristics of the state that contribute to the prevailing electricity price in the state. The price of electricity in a state is influenced by factors such as the types of units used to generate electricity, the price and availability of fuel, the geographic proximity to these resources, heterogenous ratemaking standards that might apply to that state, or the degree to which ratemaking authority is centralized ${ }^{10}$. Because generating units are long-lived assets, the composition of the generating fleet will change little over time leading to stability in the structure used to produce electricity. As a result, we might expect price levels to differ by state, and these differences to persist. Figure 2 illustrates the electricity prices in the data set for three sample states. Idaho's low prices are the result of the abundance of inexpensive hydropower resources in the region. Georgia relies primarily on coal and nuclear generation and thus experiences higher prices than Idaho. Connecticut relies on nuclear and natural gas generation, with no access to lower priced coal generation, and therefore has the highest prices of the three states.

\footnotetext{
${ }^{10}$ State public utility commissions typically have ratemaking authority over only privately owned utilities, while municipally-owned utilities are governed by the municipalities themselves, and cooperative utilities are governed by the customers they serve.
} 


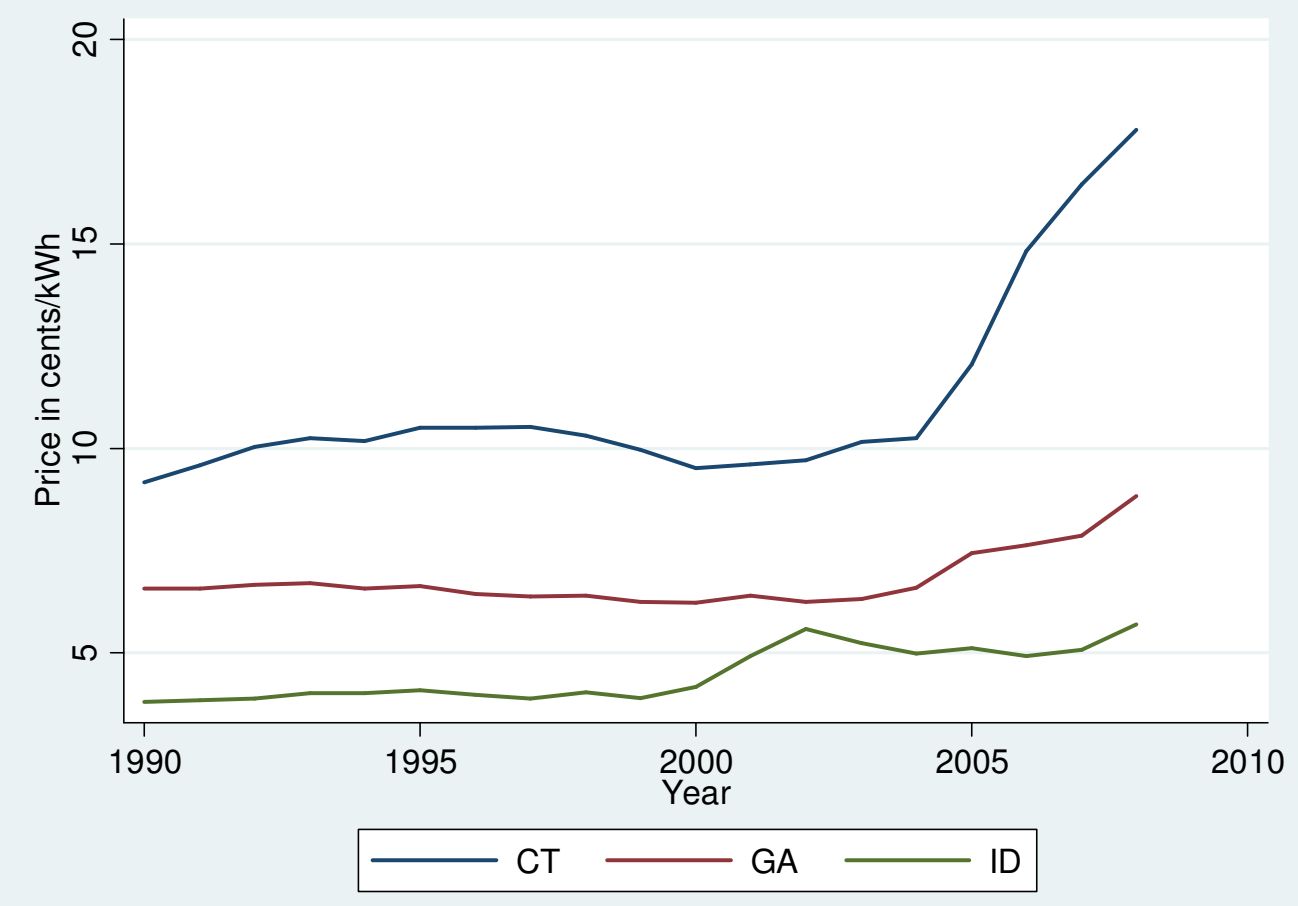

Figure 2. Comparative State Electricity Prices

We can remove the heterogeneous effects of this variable $\alpha$ by estimating the model in first differences. Further, we transform the variables Price, Sales, Coal, and Gas by taking logs, so that the variables in the equation all represent annual percent changes. The estimation equation then becomes:

$$
\begin{aligned}
\text { InPrice }_{i t}= & \beta_{0} \Delta \text { lnSales }_{i t}+\beta_{1} \Delta \text { lnPCoal }_{i t}+\beta_{2} \Delta \text { lnPGas }_{i t}+\beta_{3} \Delta \% \text { Hydro }_{i t}+\beta_{4} \Delta \% \text { Nuc }_{i t} \\
& +\beta_{5} \Delta R T O_{i t}+\beta_{6} \Delta R T O_{i t-1}+\beta_{7} \Delta R T O_{i t-2}+u_{i t}
\end{aligned}
$$

We have added lagged observations of the RTO variable in the estimated model, as the effects of the RTO may not materialize (or fully materialize) in the first year. Unless the price elasticity of electricity demand is zero, we would expect the electricity sales variable to be endogenous in the price equation. While other authors have estimated the price elasticity of 
demand for electricity ${ }^{11}$, that question is beyond the scope of this paper. As long as the price elasticity differs from zero, it is important for the specification of this model. Therefore, we have tested the endogeneity of the electricity sales variable using the instrumental variables heating and cooling degree days and state population. Even if the price of electricity has an effect on sales, it should not have an effect on the weather or the population of the state, so these variables are exogenous. We estimated the reduced form equation for $\Delta \ln S a l e s$ and included the residuals as explanatory variables in equation (2). The coefficient on this variable was significant ${ }^{12}$, and so we have estimated equation (2) using 2SLS with the instrumental variables heating and cooling degree days and state population for Sales.

The sign of the Sales coefficient might be positive or negative. Increased demand for electricity increases the expenditure on fuels required to produce electricity and may result in the utilization of higher cost generating units, which would have the effect of increasing price. However, utilities generally recover some amount of fixed costs through variable charges, so a decrease in sales could also have the effect of raising prices overall, as any fixed costs need to be recovered over a smaller volume of sales. Increasing fuel prices, the primary variable cost of electricity production, should also cause prices to increase, so the signs on Coal and Gas coefficients should be positive, as many utilities recover fuel expenditures as they are incurred through fuel adjustment charges in their retail rates. The variable costs associated with the production of hydroelectricity are very low, but the availability of hydroelectricity varies with year to year levels of precipitation, realized as either rainfall or accumulated snow pack. However, when the electricity is available, it is available at much lower variable costs. Therefore, we should expect the sign on \%Hydro to be negative, as increased volumes of

\footnotetext{
${ }^{11}$ See, for example, Bernstein and Griffin (2005)

12 The details of the reduced form estimation are included in Appendix A
} 
hydroelectricity should displace more expensive generating resources. The sign on $\% N u c$ should also be negative, as increased availability of low priced nuclear generation should result in lower electricity prices.

\section{$5 \quad$ Results}

The results of the estimation of equation (2) are shown in Table 1.

\begin{tabular}{|c|c|}
\hline \multicolumn{2}{|c|}{ Table 1: 2SLS Estimates with Entire Sample } \\
\hline Variable & Coefficient \\
\hline Constant & $\begin{array}{l}0.0192 * * * \\
(0.0030)\end{array}$ \\
\hline AlnSales & $\begin{array}{l}-0.1058 \\
(0.0979)\end{array}$ \\
\hline$\triangle \ln P$ Coal & $\begin{array}{l}0.1622 * * * * \\
(0.0271)\end{array}$ \\
\hline$\triangle \ln P G a s$ & $\begin{array}{l}0.0206^{* * * *} \\
(0.0076)\end{array}$ \\
\hline$\triangle \% H y d r o$ & $\begin{array}{l}-0.1714 * * * * \\
(0.0548)\end{array}$ \\
\hline$\Delta \% N u c$ & $\begin{array}{l}-0.0147 \\
(0.0182)\end{array}$ \\
\hline RTO & $\begin{array}{l}-0.0202 * * \\
(0.0089)\end{array}$ \\
\hline $\mathrm{RTO}_{\mathrm{t}-1}$ & $\begin{array}{l}-0.0286^{* * * *} \\
(0.0093)\end{array}$ \\
\hline $\mathrm{RTO}_{\mathrm{t}-2}$ & $\begin{array}{l}-0.0043 \\
(0.0126)\end{array}$ \\
\hline (Robu & $\begin{array}{l}\text { in parentheses) } \\
0 \% \text { level } \\
5 \% \text { level } \\
99 \% \text { level }\end{array}$ \\
\hline
\end{tabular}

The coefficient on sales is negative, but not statistically significant. The coefficients for the fuel prices both have the expected signs and are statistically significant at the 99\% level, though the electricity price is eight times more sensitive to a $1 \%$ increase in coal prices than to a natural gas price increase. It is a common approach, in modeling electric prices, to form a fossil 
fuel price index ${ }^{13}$ and use it as a proxy for fuel costs. The fact that the coefficients for natural gas prices and coal prices are significant and distinct in our specification suggests that modeling fuel prices in this manner is conveying information that would be unavailable if we adopted the fossil fuel index approach. Increased availability of hydroelectricity causes the price to decrease, and this decrease is significant. And finally, as indicated by the sum of the coefficients on the RTO and $\mathrm{RTO}_{\mathrm{t}-1}$ variables, electricity prices seem to fall by about $4.9 \%$ during the first two years of an RTO's existence. The coefficient associated with the $\mathrm{RTO}_{\mathrm{t}-2}$ variable is not statistically significant, and further lags of the variable yield similar results. This indicates that if an RTO is going to have a price impact on consumers, it occurs in the first two years of its existence. This 4.9\% decrease is statistically significant and interesting, because it is at the lower range identified by Joskow (2006), who estimates the price effects of electric restructuring, utilizing a different data set and methodology, to be $5 \%$ to $10 \%$.

However, as noted by Kwoka (2006), the effects of restructuring settlements and any imposed rate caps that accompanied those settlements can act as confounding factors, by masking the market prices that might otherwise exist if not for the restructuring agreement. That is, when we estimate the equation with the full sample, the effects of RTOs are indistinguishable from the effects of these rate agreements, if membership in an RTO accompanies the restructuring. We would like to be able to simply account for these rate agreements with additional variables, but the form of these agreements, such as the length of time that rate controls are put in place, the restrictiveness of these controls, and the period over which these deferred costs are recovered, differs greatly from state to state, making the quantification of their

\footnotetext{
${ }^{13}$ This index is essentially a weighted average of coal and natural gas prices, as states do not use appreciable quantities of petroleum to generate electricity.
} 
effects difficult. Therefore, we have concluded that the best way to account for these effects is to remove them altogether.

To remove this confounding effect, we have estimated the equation with only the sample of states that have not restructured their electric industry. This means that our sample is free of any of the confounding effects of rate agreements on electricity prices, and should truly reflect the effects of RTOs. Note that membership in an RTO does not require restructuring of the electric utility, as the RTO does not assume ownership of the transmission and distribution assets of the utility, so we will have states in our sample that are within RTOs, but have not restructured their electric industry. The results of the estimation of equation (2) with this restricted sample are shown in Table 2.

\begin{tabular}{|c|c|}
\hline \multicolumn{2}{|c|}{$\begin{array}{l}\text { Table 2: 2SLS Estimates Excluding States that } \\
\text { have Restructured their Electric Industry }\end{array}$} \\
\hline Variable & Coefficient \\
\hline Constant & $\begin{array}{l}0.0140 * * * \\
(0.0032)\end{array}$ \\
\hline AlnSales & $\begin{array}{l}-0.0511 \\
(0.1156)\end{array}$ \\
\hline$\Delta \ln P$ Coal & $\begin{array}{l}0.1777^{* * * *} \\
(0.0362)\end{array}$ \\
\hline$\Delta \ln P G a s$ & $\begin{array}{l}0.0264 * * * \\
(0.0080)\end{array}$ \\
\hline$\Delta \% H y d r o$ & $\begin{array}{l}-0.2058^{* * * *} \\
(0.0749)\end{array}$ \\
\hline$\Delta \% N u c$ & $\begin{array}{c}0.0552 \\
(0.0556)\end{array}$ \\
\hline RTO & $\begin{array}{l}-0.0127 \\
(0.0086)\end{array}$ \\
\hline $\mathrm{RTO}_{\mathrm{t}-1}$ & $\begin{array}{l}-0.0126 \\
(0.0107)\end{array}$ \\
\hline $\mathrm{RTO}_{\mathrm{t}-2}$ & $\begin{array}{c}0.0043 \\
(0.0094)\end{array}$ \\
\hline \multicolumn{2}{|c|}{$\begin{array}{l}\text { R-squared of } 0.21 \\
\text { (Robust standard errors clustered by state in parentheses) } \\
* \text { Statistically significant at the } 90 \% \text { level } \\
* * \text { Statistically significant at the } 95 \% \text { level } \\
* * * \text { Statistically significant at the } 99 \% \text { level }\end{array}$} \\
\hline
\end{tabular}


Notice that the signs and significance of most of the variables remains unchanged when we estimate the model with this subset of the data. The magnitudes of the coefficients are consistent as well. However, the variables corresponding to the establishment of an RTO and the effects of that RTO one year later have changed considerably. First, the magnitude of the variables related to the RTO has fallen by roughly half, and second, the precision of their measurement has changed as well. Neither variable is significant at even the $90 \%$ level. Therefore, by eliminating from the sample those 16 states that have restructured their electric industry, we have seen the price effects of an RTO reduced from approximately $4.9 \%$, significantly different from $0 \%$, to $2.5 \%$, but not significantly different from $0 \%$. This suggests that most of the realized price reductions observed in our initial estimation are not due to the change in the market structure, but the form of the restructuring agreements in the states that chose to restructure their markets. Therefore, if there are any cost savings that result from the establishment of RTOs in the absence of electric restructuring, they are not significantly different from zero.

We have tested alternate specifications of this model, both as a check on the robustness of the results as well as a way to relax certain assumptions of the original specification of the model. First, we have considered the effects of RTO membership on real prices instead of nominal prices. Using the annual consumer price index from the Department of Labor's Bureau of Labor Statistics, we have restated all of the electricity and fuel prices in real terms. Replacing nominal prices with real prices decreases the magnitude of the price effects, as we would expect once the effects of inflation are removed, but does not change the results regarding statistical significance. $^{14}$

\footnotetext{
${ }^{14}$ Estimation details are available upon request from the author.
} 
Second, the original model, as specified, assumes that the marginal effect of changes in fuel price does not vary by state. However, because the availability of resources necessary to generate electricity varies with individual state geography, the degree to which each state relies on different types of fuels changes. Therefore, this assumption that marginal effects are constant across states may not be valid. Therefore, we have estimated another specification of the model with interaction terms between each state and the price of coal and natural gas in that state.

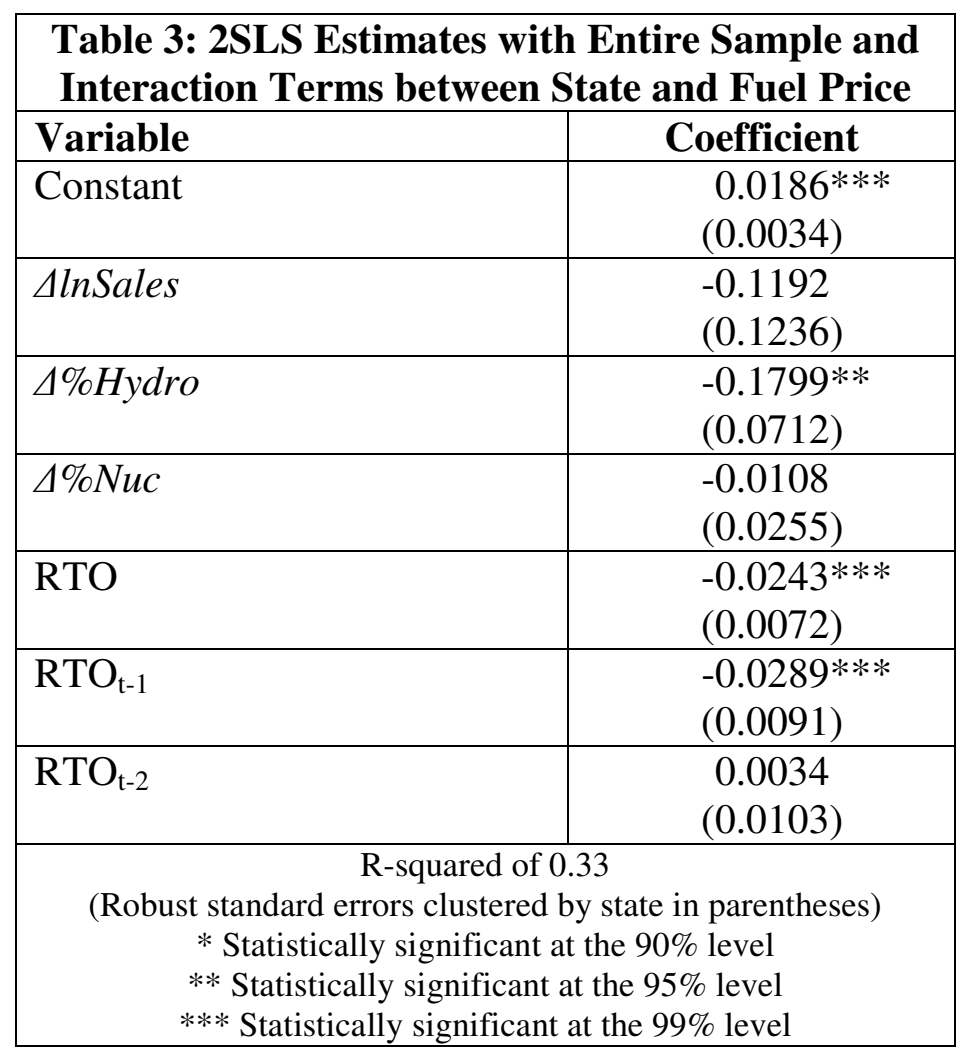

The 96 coefficients for the state and fuel price interaction have been omitted from this table for the sake of parsimony, but a Wald test rejects the hypothesis that the coefficient of each state with respect to coal prices are equal at the $99 \%$ level, and a test of the coefficients on gas 
prices yields similar results. For illustrative purposes, we have listed selected coefficients in Table 4 below $^{15}$.

\begin{tabular}{|c|c|}
\hline \multicolumn{2}{|c|}{$\begin{array}{l}\text { Table 4: Selected Coefficients on the Interaction } \\
\text { between State and Fuel Prices }\end{array}$} \\
\hline State & Coefficient \\
\hline \multicolumn{2}{|c|}{ Change in Log Coal Prices } \\
\hline Alabama & $\begin{array}{l}0.3930 * * * \\
(0.0248)\end{array}$ \\
\hline Florida & $\begin{array}{l}0.4407 * * \\
(0.1958)\end{array}$ \\
\hline Georgia & $\begin{array}{l}0.4338 * * * \\
(0.0701)\end{array}$ \\
\hline Minnesota & $\begin{array}{l}0.2562 * * * \\
(0.0373)\end{array}$ \\
\hline \multicolumn{2}{|c|}{ Change in Log Natural Gas Prices } \\
\hline Colorado & $\begin{array}{l}0.0662 * * \\
(0.0336)\end{array}$ \\
\hline Louisiana & $\begin{array}{l}0.2002 * * * \\
(0.0289)\end{array}$ \\
\hline Oklahoma & $\begin{array}{l}0.1363 * * * \\
(0.0401)\end{array}$ \\
\hline Texas & $\begin{array}{l}0.1718 * * * \\
(0.0472)\end{array}$ \\
\hline \multicolumn{2}{|c|}{$\begin{array}{c}\text { (Robust standard errors clustered by state in parentheses) } \\
* \text { Statistically significant at the } 90 \% \text { level } \\
\text { ** Statistically significant at the } 95 \% \text { level } \\
\text { *** Statistically significant at the } 99 \% \text { level }\end{array}$} \\
\hline
\end{tabular}

This specification of the model controls for the heterogeneity of each state's sensitivity to fuel prices, and the coefficients are consistent with the degree to which these states rely on these fossil fuels. As of 2008, $37 \%$ of Alabama's generating capacity was coal-fired, as was $18 \%$ of Florida's generating capacity, and 36\% of Georgia's and Minnesota's. Colorado relies on natural gas for $44 \%$ of its generating capacity, while Louisiana, Oklahoma, and Texas are much more reliant on gas with $76 \%, 65 \%$, and $69 \%$ of their capacity, respectively. It is not surprising, then, that the electricity prices in these states would be sensitive to the prices of these fuels. The

\footnotetext{
${ }^{15}$ The coefficients for all 96 interaction terms are available from the author upon request.
} 
addition of these variables does not change the results of our analysis, however, as shown in the restricted sample regression results in Table 5 below.

\begin{tabular}{|c|c|}
\hline \multicolumn{2}{|c|}{$\begin{array}{l}\text { Table 5: 2SLS Estimates with Restricted Sample } \\
\text { and Interaction Terms between State and Fuel } \\
\text { Price }\end{array}$} \\
\hline Variable & Coefficient \\
\hline Constant & $\begin{array}{c}0.0113 * * * \\
(0.0033) \\
\end{array}$ \\
\hline$\Delta \operatorname{lnSales}$ & $\begin{array}{l}-0.0149 \\
(0.1195)\end{array}$ \\
\hline$\Delta \%$ Hydro & $\begin{array}{l}-0.1896^{*} \\
(0.1081)\end{array}$ \\
\hline$\Delta \% N u c$ & $\begin{array}{c}0.0336 \\
(0.0583)\end{array}$ \\
\hline RTO & $\begin{array}{l}-0.0155^{*} \\
(0.0081)\end{array}$ \\
\hline $\mathrm{RTO}_{\mathrm{t}-1}$ & $\begin{array}{l}-0.0025 \\
(0.0081)\end{array}$ \\
\hline $\mathrm{RTO}_{\mathrm{t}-2}$ & $\begin{array}{c}0.0076 \\
(0.0058)\end{array}$ \\
\hline \multicolumn{2}{|c|}{$\begin{array}{c}\text { R-squared of } 0.34 \\
\text { (Robust standard errors clustered by state in parentheses) } \\
* \text { Statistically significant at the } 90 \% \text { level } \\
* * \text { Statistically significant at the } 95 \% \text { level } \\
* * * \text { Statistically significant at the } 99 \% \text { level }\end{array}$} \\
\hline
\end{tabular}

The individual state interaction terms change slightly, but remain largely consistent between the two samples. Once again, the effect of the RTO is reduced dramatically, as is the precision with which it is measured. However, with this specification, we do see a reduction of approximately $1.5 \%$ in realized electricity prices, and this result is significant at the $90 \%$ level.

Finally, the state data set also includes prices and sales reported by broad customer class (i.e. residential, commercial, and industrial customers). To see if benefits from RTOs have accrued to particular customer classes, we have again estimated the price equation using the prices and sales for each class of customer and report the results in Table 6. The coefficients are similar in sign and magnitude to the ones in Table 2, but now we do find two statistically 
significant results for the RTO variables. The first is a $1.39 \%$ decrease in prices for residential customers in the first year of the RTO's existence. The second is a $2.61 \%$ decrease in prices for industrial customers in the second year of the RTO's existence. This provides evidence that for certain types of customers, the change in market structure may be producing tangible cost benefits. However, if the change in market structure was politically driven by a particular class of customers, they have not seen a sizable reduction in price.

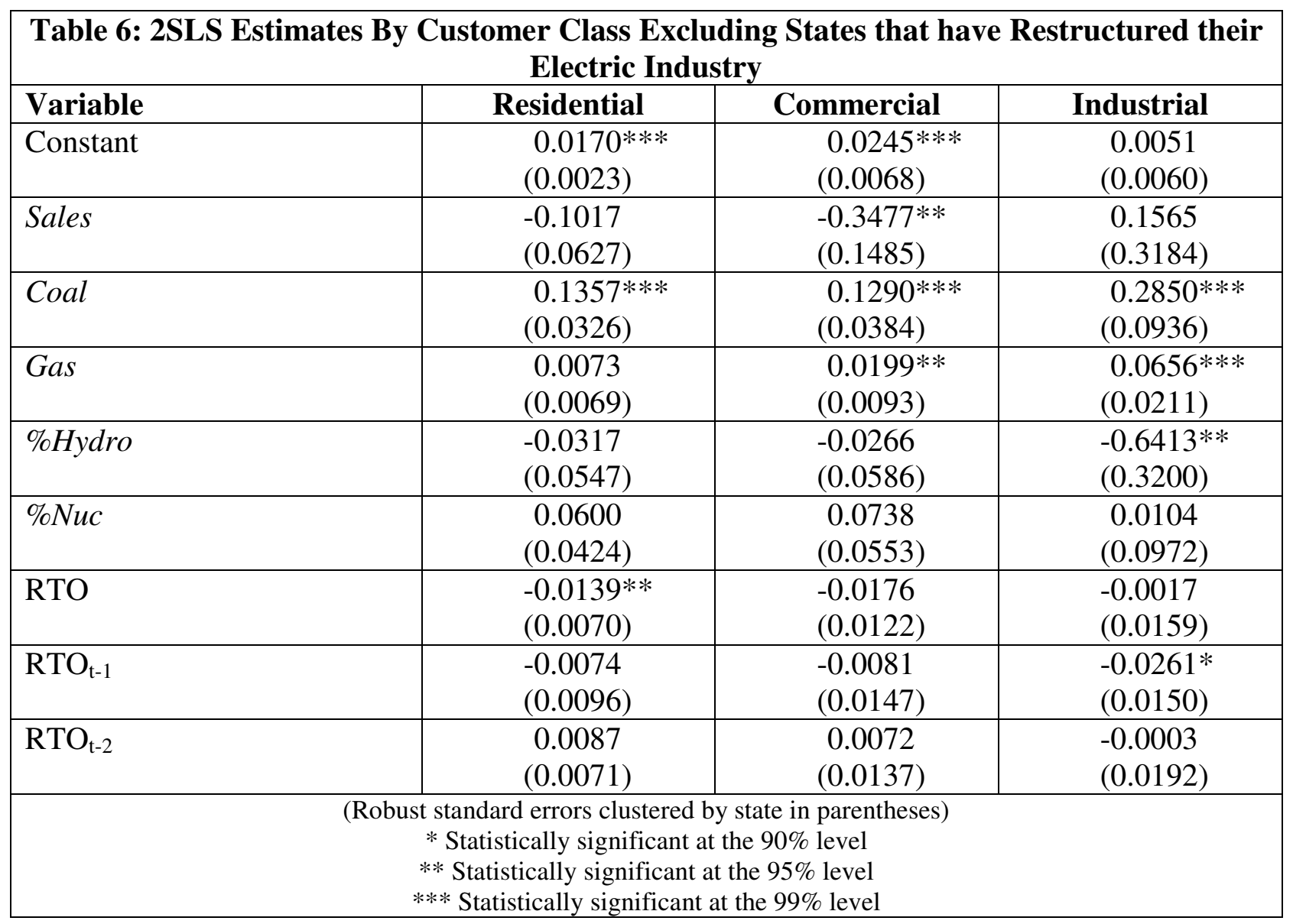

\section{Conclusion}

When the FERC established rules to change the structure of the electricity market, it did so under the assumption that the existing system was inefficient, and that the change in structure 
would provide benefits to consumers. Ten years after these original orders, the question regarding benefits of the changes in market structure was raised by the Government Accounting Office, leading to a FERC Request for Comment on the establishment of performance metrics for ISOs and RTOs. Once these data have been collected, greater insight into the net benefits of the establishment of ISOs and RTOs may be possible.

However, the present study provides some immediate insight into this important issue. Utilizing a panel data set of the United States over the past 18 years, we have estimated equations for annual percentage changes in electricity price, and attempted to identify the degree to which membership in an RTO affects costs. We have found a significant effect, a decrease of $4.9 \%$ over two years, when estimating these price changes with the full data sample. However, the full sample includes the effects of rate agreements that accompanied restructuring agreements in states that chose to restructure their market. When we estimate the equation excluding the states that restructured their electric industry, the significance of the price change disappears. Therefore, if ISOs and RTOs have led to changes in the price of electricity, then these changes are indistinguishable from zero or may only apply to certain classes of customer. However, there may be other benefits of RTOs relating to reliability of electricity service or the optimization of long term resource planning that we have not attempted to estimate here. Given the time and effort required to comply with the changes in market structure necessitated by the FERC rules, it is worth asking the question whether all of this effort has provided tangible benefits to electricity consumers.

\section{Appendix A}

To test whether $\Delta \ln$ Sales is endogenous in equation (2), we estimated the equation 


$$
\begin{aligned}
\text { AlnSales }=\beta_{0} \Delta \ln P o p & +\beta_{1} \Delta \ln C D D+\beta_{2} \Delta \ln H D D+\beta_{3} \Delta \ln P \text { Coal }+\beta_{4} \Delta \ln P G a s \\
& +\beta_{5} \Delta \% \text { Hydro }+\beta_{6} \Delta \% N u c+\beta_{7} \Delta R T O+\beta_{8} \Delta R T O_{t-1}+\beta_{9} \Delta R T O_{t-2}+\varepsilon_{i t}
\end{aligned}
$$

Where:

Pop State population

$C D D \quad$ State population-weighted cooling degree days

$H D D \quad$ State population-weighted heating degree days

Sales Electricity sales

PCoal Nominal price of coal

PGas Nominal price of natural gas

\%Hydro Percent of electric generation from hydroelectric sources

$\%$ Puc Percent of electric generation from nuclear sources

RTO Whether the majority of the electric customers in the state are served by a utility that belongs to an RTO

The results of this estimation are shown in Table 7 . We then included the residuals from this reduced form estimation as independent variables in the estimation of equation (2). The coefficient on the residuals was significant at the $99 \%$ level $^{16}$, indicating that the variable Sales is endogenous in equation (2). Therefore, we have estimated equation (2) with the two stage least squares technique (2SLS) utilizing the variables $\Delta \ln H D D, \triangle \ln C D D$, and $\triangle \ln P o p$ as instrumental variables for $\Delta \ln$ Sales.

\footnotetext{
${ }^{16}$ Coefficient was -0.5964 with a standard error of 0.1200
} 


\begin{tabular}{|c|c|}
\hline \multicolumn{2}{|c|}{$\begin{array}{c}\text { Table 7: OLS Estimates of the Log Return of } \\
\text { Electric Sales }\end{array}$} \\
\hline Variable & Coefficient \\
\hline Constant & $\begin{array}{l}0.0143 * * * \\
(0.0018)\end{array}$ \\
\hline$\triangle \ln P o p$ & $\begin{array}{l}0.6163 * * * \\
(0.0797)\end{array}$ \\
\hline$\triangle \ln C D D$ & $\begin{array}{l}0.0406^{* * * *} \\
(0.0054)\end{array}$ \\
\hline$\triangle \ln H D D$ & $\begin{array}{l}0.0901 * * * \\
(0.0151)\end{array}$ \\
\hline$\triangle \ln P$ Coal & $\begin{array}{l}-0.0395^{*} \\
(0.0147) \\
\end{array}$ \\
\hline$\triangle \ln P G a s$ & $\begin{array}{l}-0.0127 * * \\
(0.0045)\end{array}$ \\
\hline$\triangle \%$ Hydro & $\begin{array}{c}0.1309^{*} \\
(0.0483)\end{array}$ \\
\hline$\Delta \% N u c$ & $\begin{array}{c}0.0022 \\
(0.0273)\end{array}$ \\
\hline RTO & $\begin{array}{l}-0.0007 \\
(0.0028)\end{array}$ \\
\hline $\mathrm{RTO}_{\mathrm{t}-1}$ & $\begin{array}{l}-0.0023 \\
(0.0035)\end{array}$ \\
\hline $\mathrm{RTO}_{\mathrm{t}-2}$ & $\begin{array}{c}0.0081 * \\
(0.0037)\end{array}$ \\
\hline \multicolumn{2}{|c|}{$\begin{array}{c}\text { R-squared of } 0.21 \\
\text { F-test statistic is } 19.49 \text { and significant at the } 99 \% \text { level } \\
\text { (Robust standard errors clustered by state in parentheses) } \\
* \text { Statistically significant at the } 90 \% \text { level } \\
\text { ** Statistically significant at the } 95 \% \text { level } \\
\text { *** Statistically significant at the } 99 \% \text { level }\end{array}$} \\
\hline
\end{tabular}




\section{References}

Bernstein, Mark A. and James Griffin. 2005. "Regional Differences in the PriceElasticity of Demand for Energy", RAND Corporation Technical Report prepared for the National Renewable Energy Laboratory

Coase, Ronald H. 1937. "The Nature of the Firm”, Economica, New Series, Vol. 4, No. 16. (Nov., 1937), pp. 386-405

Fabrizio, Kira R., Nancy L. Rose, and Catherine D. Wolfram. 2007. "Do Markets Reduce Costs? Assessing the Impact of Regulatory Restructuring on U.S. Electric Generation Efficiency", American Economic Review Vol. 97, No. 4 (2007), pp. 1250-1277

Greenfield, Daniel, and John Kwoka. 2010. "The Cost Structure of Regional Transmission Organizations", Northeastern University Working Paper

Grossman, Sanford J., and Oliver D. Hart. 1986. "The Costs and Benefits of Ownership: A Theory of Vertical and Lateral Integration”. Journal of Political Economy 94(4), pp. 691-719.

Joskow, Paul. 2006. "Markets for Power in the United States: An Interim Assessment." Energy Journal, January 2006.

Kwoka, John. 2006. "Restructuring the U.S. Electric Power Sector: A Review of Recent Studies", Report Prepared for the American Public Power Association

Kwoka, John, Michael Pollitt, and Sanem Sergici. 2010. "Divestiture Policy and Operating Efficiency in U.S. Electric Power Distribution”. Journal of Regulatory Economics 38(2010), pp. 86-109

National Climatic Data Center, NOAA. Historical Climatological Series 5-1 and 5-2

Papalexopoulos, Alex D., and Timothy C. Hesterberg. 1990. “A Regression-Based Approach to Short-Term System Load Forecasting”. IEEE Transactions on Power Systems 5(4), November 1990, pp.1535-1550

Taber, John, Duane Chapman, and Tim Mount. 2006. "Examining the Effects of Deregulation on Retail Electricity Prices”. Cornell University Working Paper, February 2006.

United States Department of the Census Population by State 1990-2009

United States Department of Energy Energy Information Administration. State Energy Data System Database 